\title{
EL FILOSOFAR SOBRE EL DERECHO COMO UNA VIRTUD MÁS ALLÁ DE LA ACADEMIA
}

\author{
Pablo Nicolai Vera
}

Alumno ayudante de Filosofía del Derecho

Universidad Católica del Norte (Sede Coquimbo)

Al momento de pensar en un tema para un trabajo como éste, que viene a cumplir con un requisito de postulación para una de las ayudantías de las cátedras de filosofía y filosofía del derecho, uno recurre a sus lecturas y a la imaginación y se encuentra con una diversidad de ideas posibles de desarrollar y con caminos alternativos a seguir. Una primera opción consiste en reproducir alguna parcialidad específica de las materias que se acostumbra abordar en dichas cátedras o abocarse a ciertos aspectos ya demasiado tratados de determinados autores. Existe, por otra parte, la posibilidad de sumergirse en cuestiones un tanto más alambicadas, buscando sintetizar, amalgamadas y apretadamente, temáticas como, por ejemplo, la deconstrucción derrideana y el derecho, la verificación en el positivismo lógico y su aplicación al derecho, sobre la ontología del lenguaje o acerca de la ética discursiva. 0 bien, en tercer lugar, hacer derroche de literatura y atrevimiento y postular un breve ensayo aventurando algo así como La ficticia necesidad del derecho.

Como se verá, ninguna de dichas opciones se han seguido aquí, al menos en su estado puro, por cuanto la primera implica limitarse a la mera repetición y acaso al fatigoso y aburrido "cortar y pegar" materias como si de un collage se tratara, la segunda alternativa hubiese exigido más espacio y tiempo y la tercera opción, aunque más atractiva en lo personal, parecía no adecuarse a las exigencias de un trabajo de investigación como el que se requería.

Es así que, dentro de los límites exigidos, hemos optado por desenvolver una reflexión sobre algunas cuestiones básicas, introductorias si se quiere, de la filosofía y de la filosofía del derecho, vinculándolas a un brevísimo análisis de la importancia de la reflexión filosófica más allá de sedes científicas y académicas. Con este objeto dividimos el trabajo en tres apartados de desarrollo, a saber, Sobre lo que sea la filosofía y el filosofar, Algo sobre la filosofía del derecho y Más allá de la academia, a lo que se suma una sucinta conclusión. Se ha buscado desarrollar los temas con cierta generalidad y algunos cuestionamientos, antes que ofrecer respuestas y soluciones definitivas, pues con ello se ha pretendido otorgarle un cierto estilo que se relacione con el discurrir propio del filosofar. 
Para los efectos de esta publicación se han efectuado algunas precisiones y se ha optado por prescindir del marco teórico y la bibliografía general, conservando las referencias bibliográficas.

\section{Sobre lo que sea la filosofía y el filosofar}

La filosofía es una de aquellas disciplinas que se interrogan por su ser al punto de tornar el problema acerca de su propia naturaleza en uno de sus objetos de estudio, esto es, en una cuestión propiamente filosófica, entre otras cosas porque no parece haber acuerdo respecto de su definición y del valor que le cabe en consecuencia. Las actuales acepciones de la palabra filosofía son de variada índole, tanto que van desde aquellas que la identifican con un medio cognoscitivo hasta las que la conforman a un determinado modo de vida. Diversos son, asimismo, los juicios de valor que se formulan: unos depositan en su ejercicio o estudio la esperanza de hallar revelaciones extraordinarias, otros la desechan sin más por quimérica o inútil; para algunos se corresponde con la cotidianeidad y con la subjetiva manera de pensar de cada cual, por lo que se asume que está -en el fondo- al alcance de todos, mientras que para otros se trata de una disciplina en extremo compleja y difícil, por lo cual ha de quedar reservada para los especialistas. La controversia por lo que sea la filosofía tiene lugar, por lo demás, a partir de las disímiles concepciones que de ella se hacen quienes, precisamente, se nos presentan como filósofos, vale decir por quienes han desarrollado o desarrollan esta actividad. Es así que, desde antiguo, este tema resulta recurrente en muchas de las obras de los filósofos y constituye una referencia obligada cuando se pretende indagar sobre el sentido del filosofar, toda vez que el pensador mismo se vuelve hacia su pensar y le confiere con ello una dimensión problemática. En efecto, aunque no podamos ocuparnos aquí sobre las múltiples respuestas que diversos autores o escuelas han dado al interrogante sobre el concepto de filosofía, sí podemos apuntar que ellas se confrontan a partir de lo que Agustín Squella sintetiza como una triple problematicidad de la filosofía, cuando expresa: "En suma, la filosofía no sabe, o no tiene suficiente seguridad, acerca de cuál es su objeto, cuál su método y cuáles las respuestas que deben ser preferidas a las demás" (1) Esto por cuanto dependerá del filósofo de que se trate cuál sea el objeto que se le asigne al quehacer filosófico, ya sea, sólo a modo ejemplar, el ser, el ente, lo fenoménico, el hecho científico, la vida como realidad radical, la conciencia, la existencia, el lenguaje. Tampoco se tiene un denominador común en cuanto al método, pues no se coincide por parte de los filósofos en cuanto a los criterios de determinación del objeto, en relación a la selección de sus problemas y a las formas de verificación y control de sus proposiciones, lo cual se pude ilustrar incluso con la simple mención de algunos nombres por los que se les suele designar: la mayé utica socrática, la dialéctica, la lógica, la disputa escolástica, la duda cartesiana, el criterio de la verificabilidad del empirismo lógico, la falsabilidad popperiana, etc.. Por último, desde la perspectiva de sus resultados, la filosofía arroja 
un sinnúmero de sistemas o doctrinas abiertamente incompatibles, sean los resultados de la doctrina platónica, el sistema aristotélico, la escuela cínica, el estoicismo, el escolasticismo, el positivismo, la filosofía analítica, la fenomenología, el existencialismo, por sólo señalar unos cuantos, en definitiva toda una miscelánea que, como es fácil comprender, impide que su presentación sea fácilmente asumida como un todo relacionado y coherente.

La polisemia de la voz filosofía, junto a los problemas referidos a su objeto, métodos y resultados, hacen que en su enseñanza práctica y en los manuales que se suelen redactar para ese fin, sea ya un lugar común el recurrir a la etimología, al desglose de la estructura de la palabra que se corresponde con las voces griegas philo y sophia, que significan en conjunto ese amor a la sabiduría que se opondría a la pura sophia, a la sabiduría. Dice Karl Jaspers que este sentido ha perdurado hasta nuestros días, pues "la busca de la verdad, no la posesión de ella, es la esencia de la filosofía, por frecuentemente que se la traicione en el dogmatismo, esto es, en un saber enunciado en proposiciones, definitivo, perfecto y enseñable" (2) Sin embargo, en esto caben otros puntos de vista, como el que predica García Morente cuando expresa que en "Herodoto, en Tucídides, quizá en los presocráticos, alguna que otra vez, durante poco tiempo, tiene este significado primitivo de amor a la sabiduría. Inmediatamente pasa a tener otro significado: significa la sabiduría misma" (3) Con ello nos quiere advertir que la filosofía constituye por entonces una clase de saber y que ese saber es aquel que se adquiere sólo si se le busca, con lo que regresa a la idea de indagación. No obstante, más provocadora parece la interpretación de Giorgio Colli, quien nos dice que la filosofía se vincula a una etapa de decadencia, dado que el amor a la sabiduría está en relación de inferioridad respecto de la sabiduría, y, en tanto que Platón llama de la primera forma a su actividad educativa, nos plantea un giro radical: "Efectivamente, amor a la sabiduría no significaba, para Platón, aspiración a algo nunca alcanzado, sino tendencia a recuperar lo que ya se había realizado y vivido" y, tras una pausa, añade: "Así pues, no hubo un desarrollo continuo, homogéneo, entre sabiduría y filosofía. Lo que hizo surgir a esta última fue una reforma expresiva, fue la intervención de una nueva forma literaria, de un filtro a través del cual quedó condicionado el conocimiento de todo lo anterior. La tradición, en gran parte oral, de la sabiduría, ya oscura y avara por la lejanía de los tiempos, ya evanescente y tenue por el propio Platón, para nosotros aparece así falsificada también por la inserción de la literatura filosófica" (4) He aquí que lo que parecía pacífico es abrasado por las llamas de la contradicción filosófica, ya que no sólo se trata de etimología, sino que, al mismo tiempo, se realiza una crítica a la cultura de un tiempo pretérito con el inevitable arraigo en la cultura actual, la cual también se pone en cuestión. Esta contradicción nos hace preguntarnos: la filosofía ¿sigue siendo una búsqueda? Si es búsqueda ¿lo es de algo conocido o desconocido? Porque si tiene razón Colli entonces Platón a lo que aspiraba era a conservar o recuperar aquella cultura de los sabios de los siglos que le precedieron, lo 
que perseguiría mediante el artilugio literario; pero una cosa es ir tras una verdad desconocida y otra muy distinta es amar la sabiduría, porque ¿ cómo se podría amar la sabiduría si no se la conoce? ¿ Cómo ser amigo de la verdad sin tener un pre-concepto de ella, sin usarla como máscara? ¿Y qué quiere el que busca la verdad? ¿Es lo mismo preguntar qué es lo verdadero y quién sostiene o impone la verdad? ¿ $Y$ por qué hemos de preferir la verdad a la no verdad? ¿Por qué tiene que haber algo en lugar de nada o viceversa? ¿ $Y$ qué somos en medio de este algo, esta nada o este todo?

Con independencia de las respuestas que pudiéramos intentar, conviene a nuestro propósito subrayar la importancia de las cuestiones que sugieren dichos planteos, pues quizá en definitiva -recordando a Kant- sea tarea imposible aprender filosofía y tan sólo podamos llegar a filosofar(5) Aquí nos interesa esto: lo que sea la filosofía supone un filosofar, una actividad que tiene su origen en ese asombro al que se refirieron Platón y Aristóteles y que conlleva el necesario reconocimiento de la ignorancia, considerando que ignorar, al decir de Savater, "es no saber nunca nada del todo ni todo de nada"(6), lo que sumado a la imaginación nos impele a lo que denomina "la tarea especulativa por excelencia: la invención" (7) En otra parte nos dice el pensador español: "Para empezar. pensar hay que perder la fe: la fe en las apariencias, en las rutinas, en los dogmas, en los hábitos de la tribu, en la normalidad indiscutible de lo que nos rodea. Pensar no es verlo todo clarísimo, sino comenzar a no ver nada claro lo que antes teníamos por evidente" (8) He aquí la duda y su experiencia, de donde se sigue el examen crítico de lo sabido, que por lo mismo adquiere un carácter siempre provisional. Filosofar equivale a formular preguntas radicales y universales desde el propio entendimiento, con esa ingenuidad que caracteriza a los niños, exenta de prejuicios, y con la rigurosidad escéptica del inconformista, de modo de garantizar la libertad del pensamiento, es decir, el ejercicio de la razón fundado en grados crecientes de inseguridad, en la medida que hace de la crítica y la autocrítica un constante devenir.

Pero tal como vimos en el caso de Jaspers, García Morente y Colli, el filosofar tiene lugar dentro de una cultura y acaso por eso la filosofía tienda a re-definirse permanentemente. A quien filosofa, sobre lo que sea, le tienta siempre la identificación con la cultura en la que convive y he ahí la amenaza contra la conciencia crítica, la que no pocas veces transfigura ciertas filosofías en discursos justificadores de lo existente $y$ legitimadores de lo vigente. Entonces la filosofía se vuelve académica, se reduce a ideología, ahora desprovista de duda y examen crítico. Por ello conviene no olvidar que lo vital del filosofar no consiste en lograr una mayor cantidad de aciertos, sino más bien en lo estimulantes y fértiles que puedan llegar a ser sus errores. De ahí la diversidad de las ideas y de los movimientos filosóficos, que no representan otra cosa que intentos de respuestas críticas tanto para las interrogaciones fundamentales de siempre como para las culturas en que tuvieron expresión. 


\section{Algo sobre la filosofía del derecho}

Asistimos a una proliferación de filosofías aplicadas, a saber, de la historia, el arte, la educación, la economía, etc., y entre ellas también a la filosofía del derecho, expresión de reciente data, la que Hegel utiliza quizá por vez primera en 1820 para intitular su obra Elementos de filosofía del derecho. También se puede decir que es relativamente nueva como disciplina y como asignatura de las carreras de derecho, pero no se puede predicar lo mismo de ella en cuanto actividad filosófica sobre el derecho, pues en este sentido acompaña a la filosofía probablemente desde sus comienzos. Ahora, si desde antiguo nos llegan noticias, sea por cronistas o por fragmentos, de un filosofar sobre el derecho, preciso es atender a la diferencia que existe entre su constitución como disciplina y como asignatura, ya que una no implica a la otra. Es decir: como disciplina filosófica es un modo de saber sobre el derecho, con cierta autonomía y delimitación de su objeto; en cambio, como asignatura significa que ocupa un lugar en un plan curricular de las facultades de derecho. Existe una relativa independencia entre ambas dimensiones, sin desconocer sus obvias interrelaciones, tanto que la disciplina puede subsistir aunque se elimine la asignatura de un determinado plan de estudio. Parece evidente que como actividad guarda la independencia propia de quienes asumen el llamado kantiano del ya clásico sapere aude(9), sin que esto signifique abolir, claro está, esa complementaria pulsión artística, ese componente imaginativo o artificioso que supone la filosofía desde una perspectiva vital, la que a su manera reivindicaron pensadores como Schelling o Nietzsche. De manera que la importancia que como asignatura tenga en la formación jurídica de los estudiantes es algo que queda sujeto a la consideración y la decisión de quienes deban resolver su pertinencia curricular, aunque para nosotros sea palmaria si recordamos las palabras de Jorge Millas: "el abogado necesita antes que memoria jurídica, inteligencia jurídica" (10) Por tanto, podemos decir que la relativa facilidad con que se podría poner fin a la filosofía del derecho vista como asignatura, se nos torna menos clara al momento de considerarla como disciplina y casi inverosímil cuando la entendemos como actividad.

Por ahora, eso sí, tenemos que la filosofía y la filosofía del derecho se relacionan, lo que está en cuestión es en qué forma. Hay quienes toman a la filosofía jurídica como una parte de la filosofía general; otros aplican una filosofía general a sus nociones, razonamientos o conclusiones filosóficas acerca del derecho; y otros, en fin, asumen la filosofía del derecho, apartándose de las vías anteriores, como una disciplina relativamente autónoma de la filosofía general. Señala Martín Diego Farrell: "el filósofo del derecho debe conocer por igual la filosofía y el derecho" (11) Pero ya vimos lo dubitable que resulta el concepto de filosofía, a lo que deberíamos agregar ahora la polivalencia del término derecho, con lo que se complica un tanto más la cuestión, lo cual no implica dejar de afirmar como necesaria una base filosófica general para la filosofía del derecho. Con todo, digamos que una semejanza entre filosofía y filosofía 
del derecho tiene que ver con el carácter problemático de su definición, así como con esa "triple problematicidad" acerca del objeto, los métodos y las respuestas, a que se refiere Squella. Empero, ello no quita la radicalidad ni la universalidad de las cuestiones y críticas que la filosofía del derecho debe hacer respecto del derecho, a condición de no perder su calidad de disciplina filosófica.

La filosofía jurídica, como parece obvio, limita su objeto al derecho, mas lo que sea el derecho es asunto controversial, de donde surge la interrogante: ¿ esta disciplina ha de esperar a que se resuelva la polémica sobre lo que sea el derecho para enseguida iniciar su tarea o es parte de su quehacer el ocuparse de lo que el derecho sea? Entramos a los temas propios de la filosofía del derecho, donde tampoco hay acuerdo, pero respecto de los cuales nos limitamos a enunciar algunas alternativas. Peces Barba, en la línea de Bobbio, se refiere a "un estudio tripartito: la Teoría de la Justicia, la Teoría del Derecho y la Teoría de la Ciencia Jurídica" (12) Del Vecchio, por su parte, aborda tres investigaciones: una lógica (sobre el concepto universal de derecho), una fenomenológica (causas universales del origen y de la historia del derecho en general) y una deontológica (crítica y valor del derecho según un ideal de justicia fundado en la pura razón) Kelsen, por su parte, circunscribe la filosofía del derecho a la filosofía moral y Alf Ross prefiere más bien referirse a problemas iusfilosóficos. Sin embargo, mayor acuerdo existe en torno al papel central que tendría la teoría de la justicia en la filosofía del derecho, donde se suman voces como las de Elías Díaz, Recasens Siches, Ruiz Jiménez, Legaz y Lacambra, Radbruch, Hart, Bobbio, Stammler, Del Vecchio, entre otros.

Vemos de este modo que el acercamiento filosófico al derecho se suele hacer desde diversas ópticas, siendo especialmente relevantes, como recuerda Manuel Atienza, el enfoque estructural (léase como referencia a la norma o a un conjunto de normas jurídicas), el realista o sociológico (léase como hecho social), el axiológico (léase como valor o deber ser) y el que lo considera como argumentación (léase como visión instrumental, pragmática y dinámica que presupone, emplea y da sentido a las anteriores) "La asunción de esta última perspectiva - destaca Atienza- tiene sir duda que ver con la cultura jurídica de cada país, esto es, con las actitudes que la gente en general y los juristas en particular tienen hacia el derecho y hacia la sociedad" (13), lo que implicaría un cierto relativismo en la propensión para asumirla, sin que por eso deje de ser una de las opciones de aproximación al fenómeno jurídico, la cual, en todo caso, como veremos, resulta del todo pertinente para nuestro actual propósito.

\section{Más allá de la academia}

Gregorio Peces Barba funda en la crítica al derecho positivo vigente la necesidad y la justificación de la filosofía del derecho, pues el reconocer que el derecho válido sea 
derecho, aunque no sea justo -no se olvide su adscripción a lo que denomina un normativismo corregido-, no supone desentenderse de lo que se estime que el derecho deba ser, dado que ello implicaría legitimar lo que Bobbio llama teoría legalista de la justicia, que reduce la justicia a validez, es decir, que considera que el derecho es justo en tanto que es válido, y él no está dispuesto a concederlo. Asimismo, esta perspectiva filosófica debe extenderse a la dogmática para efectos de no mutilar la reflexión sobre el concepto del derecho de su dimensión crítica y además enderezarse a las cuestiones metodológicas y epistemológicas que se suscitan. De este modo vamos viendo que el cultivo de la filosofía del derecho tiene importancia para una sólida formación jurídica, en la medida que fortalece y aclara los juicios para enfrentar el fenómeno jurídico y sobretodo porque lo asume no sólo como una realidad normativa, sino que también fáctica y valorativa. Ahora, desde la teoría dinámica del derecho(14), que nos obliga a desplazar la mirada desde el ordenamiento jurídico hacia los procesos y operaciones en virtud de las cuales se generan, interpretan, aplican y acatan sus normas, tenemos que los denominados operadores jurídicos (legisladores, jueces, funcionarios de la administración, abogados, sujetos imperados y mediadores), que participan de estos procesos, llevan a cabo razonamientos jurídicos, de donde tenemos que la adecuada comprensión o el ejercicio intelectual que conlleva la reflexión filosófica sobre el derecho resulta relevante también en la vida de la ciudad, pues esos razonamientos se manifiestan a través del discurso jurídico, el que no es sino un caso especial del discurso práctico general, lo que fundamenta Robert Alexy: "(1) en que las discusiones jurídicas se refieren a cuestiones prácticas, es decir, a cuestiones sobre lo que hay que hacer u omitir, o sobre lo que puede ser hecho u omitido, y (2) estas cuestiones son discutidas desde el punto de vista de la pretensión de corrección. Se trata -prosigue- de un caso especial, porque la discusión jurídica (3) tiene lugar bajo condiciones de limitación" (15) Cabe aclarar que dicha pretensión de corrección se refiere a que las proposiciones normativas puedan ser racionalmente fundamentadas en el marco del ordenamiento jurídico vigente, el que viene a configurar, a su vez, las limitaciones propias del discurso jurídico, incluido el caso de aplicación de una ley irracional, dado que si en una situación tal no se ha podido determinar racionalmente el contenido de la decisión, ello no es óbice para admitir como plausible que la racionalidad discursiva "conforma la razón para su incorrección y la medida para su crítica" (16).

Estamos en el ámbito de la argumentación jurídica y en un contexto de derecho vigente. Si juristas, profesores y alumnos producen argumentaciones jurídicas, lo hacen como clase especial de razonamiento teórico, aunque no desconocemos que puedan llegar a tener alcances prácticos. Lo que interesa aquí es la argumentación como tipo especial de razonamiento práctico, aquel encaminado a obtener y ofrecer la justificación de alguna decisión o acción y que nos lleva más allá de las sedes científicas y de las aulas pedagógicas, dado que su valor no se circunscribe a una explicación conceptual ni a un criterio de corrección hipotético, sino que sus formas y reglas 
pueden servir para contrastar las limitaciones que requieran las diversas decisiones jurídicas, ya sea en el proceso, en la legislatura o en la administración, así como en todo lugar donde la multiplicidad de los operadores jurídicos sean llamados a intervenir. Lo que nos interesa es comprender todo esto de la filosofía del derecho y, más precisamente, el filosofar sobre éste, en el sentido que vimos más arriba, como parte integrante de una cultura jurídica, donde se va más allá tanto de la retentiva y el ejercicio memorístico como más allá de los meros tecnicismos legales, para situarnos en un sentido de responsabilidad social que no se agota siquiera en los límites de la dogmática jurídica, sino que se expresa en la vivencia de la reflexión filosófica y que, consecuentemente, se traduce en un accionar polémico inconformista que puede contribuir al perfeccionamiento de la convivencia cívica. Respondiendo a una pregunta acerca del rol de los jueces en la protección de los derechos humanos, formulada en el seno de una conferencia por él dictada, Ronald Dworkin, decía: "La labor de la filosofía jurídica consiste, a mi entender, en el intento de encontrar, o de encajar en las estructuras, los principios que podemos defender y respetar, de los que podemos sentirnos orgullosos y decir: ésas son las tradiciones de nuestro acervo jurídico" (17) y con un criterio pragmático agregaba más adelante, a propósito de que jueces pudiesen aplicar una amnistía cuestionable en caso de violaciones a los derechos fundamentales, lo siguiente: "Hemos de conseguir que el asunto sea abordado con un mayor grado de sofisticación. ¿Quieren propiciar un debate en las facultades de derecho? ¿ Un debate en la prensa? ¿ Un debate en los tribunales? ¿Y un debate serio en torno a este asunto? (...) Ahora bien, no se puede encarcelar a un juez porque no hava escrito una opinión, o porque emita por escrito alguna otra en extremo insatisfacturia, pero sí se puede crear una cultura en la que el juez quede en una situación embarazosa por no enfrentar ciertas preguntas de envergadura, porque su labor resulta absolutamente insatisfactoria como jurista" (18) Se trata así de un filosofar como virtud, en el sentido de há bito pero a la vez en su significación de fuerza, de vigor, en este caso como fortaleza, si se quiere, de la formación jurídica, donde el razonamiento jurídico se despliega para persuadir o convencer con su propio peso.

"La inteligencia -dice Lazare Bickel- es nuestra facultad de no llevar hasta el límite lo que pensamos, con el fin de que podamos seguir creyendo en la realidad" (19) Pues bien, si en algún grado esto es así, quizá el pensamiento deba siempre hacer un esfuerzo más para no anclarse, para no tornarse un fósil de museo o un patrón de conducta a-crítico y ortodoxo. Más allá de la filosofía academizada, vuelta ideología, está la persona humana roída por interrogaciones esenciales de las que no escapa la organización social ni, por lo mismo, el derecho. Como escribiera para sí Marco Aurelio: "¿Te hallas dotado de razón? -Sí.- Luego ¿ por qué no usas de ella? Si cumple una función ¿Qué otra cosa pretendes?" (20) 


\section{A modo de conclusión}

Ireneo Funes, el memorioso, es un personaje de Jorge Luis Borges que tras un accidente -perder y recobrar el conocimiento, quedando postrado a perpetuidad- se encuentra viviendo un presente "casi intolerable de tan rico y tan nítido, y también de las memorias más antiguas y más triviales", respecto del cual el narrador relata: "Podía reconstruir todos los sueños, todos los entresueños. Dos o tres veces había reconstruido un día entero; no había dudado nunca, pero cada reconstrucción había requerido un día entero". Una memoria más que prodigiosa, más que extraordinaria, capaz de reconstruir hasta el más mínimo detalle, sin lugar para el olvido. No obstante, el narrador reflexiona: "Había aprendido sin esfuerzo el inglés, el francés, el portugués, el latín. Sospecho, sin embargo, que no era muy capaz de pensar. Pensar es olvidar diferencias, es generalizar, es abstraer. En el abarrotado mundo de Funes no había sino detalles, casi inmediatos" (21)

Esta ficción borgeana nos deja una lección: memorizar no es lo mismo que pensar, Sabemos que la memoria nos ayuda a pensar, pero pensar es ir más allá, como lo es el pensar filosóficamente. Hemos querido terminar con estos ingredientes literarios, porque el ejercicio del filosofar se funda en una ignorancia que unida al afán comunicativo nos lleva también a los territorios de la invención, esa actividad especulativa por excelencia a que nos referíamos con Savater. Filosofar sobre el derecho es querer saber, aunque también desplegar la imaginación para innovar, pues lo interesante de saber algo consiste, para quien no se conforma con dejar su embarcación en el atolladero, en que nos abre nuevos espacios de ignorancia donde indagar y atreverse a saber un tanto más.

\section{NOTAS BIBLIOGRÁFICAS}

1) SQUELLA NARDUCCI, Agustín, Filosofía del derecho, Editorial Jurídica de Chile, Santiago, 2001, pág. 26

2) JASPERS, Karl, La filosofía, Fondo de Cultura Económica, México, 1996. pág. 11

3) GARCÍA MORENTE, Manuel, Lecciones preliminares de filosofía, Editores Mexicanos Unidos, S.A., México, 1987, págs. 12 y 13

4) COLLI, Giorgio, El nacimiento de la filosofía, Tusquets Editores, S.A., Barcelona, España, 2000, pág. 14

5) KANT, Inmanuel, Crítica de la razón pura, Ediciones Alfaguara, Madrid, España, 1998. Cabe aquí señalar la especificación de Kant en el sentido de que filosofar es: "ejercitar el talento de la razón siguiendo sus principios 
generales en ciertos ensayos existentes, pero siempre salvando el derecho de la razón a examinar esos principios en sus propias fuentes y a refrendarlos y rechazarlos".

6) SAVATER, Fernando, El contenido de la felicidad, Santillana, S.A., España, 1996, pág. 66

7) SAVATER, F. Op. cit., pág. 66

8) SAVATER, Fernando, Libre mente, Espasa Calpe, S.A., Madrid, España, 1995, pág. 177

9) sapere aude: atrévete a saber, frase con la cual Kant invita a salir de la minoría de edad del pensamiento que se corresponde con la ignorancia.

10) En SQUELLA, A., op. cit., pág. 183

11) FARRELL, Martín Diego, La metodología del positivismo lógico. Su aplicación al derecho, Editorial Astrea, Buenos Aires, Argentina, 1979, pág. 15

12) PECES BARBA, Gregorio, Introducción a la filosofía del derecho, Editorial Debate, S.A., Madrid, España, 1993

13) ATIENZA, Manuel, Derecho y argumentación, Universidad Externado de Colombia, 1997, págs. 23 y 24

14) Se debe tener presente que aquí la teoría dinámica se refiere al ordenamiento jurídico en movimiento y no a la distinción kelseniana entre principios diná micos y estáticos.

15) ALEXY, Robert, Teoría de la argumentación jurídica, Centro de Estudios Constitucionales, Madrid, España, 1989, págs. 206 y 207

16) ALEXY, Robert, op.cit., pág. 317

17) DWORKIN, Ronald, en conferencia dictada en la Facultad de Derecho de la Universidad de Chile el 16 de diciembre de 1993, Corporación Nacional de Reparación y Reconciliación, pág.92

18) DWORKIN, R., op. cit., pág. 102

19) Citado por Albert Camus en El hombre rebelde, Alianza Editorial, S.A., Madrid, España, 1996, pág. 358 
20) MARCO AURELIO, Meditaciones, Editorial Debate, S.A., Barcelona, España, 2000, pág. 55

21) BORGES, Jorge Luis, en Artificios, Alianza Editorial, S.A., Madrid, España, 1995 